\title{
A 10-year appraisal of cesarean delivery and the associated fetal and maternal outcomes at a teaching hospital in southeast Nigeria
}

This article was published in the following Dove Press journal:

International Journal of Women's Health

13 May 2015

Number of times this article has been viewed

\section{Robinson Chukwudi Onoh' Justus Ndulue Eze ${ }^{2}$ Paul Olisaemeka Ezeonu' Lucky Osaheni Lawani' Chukwuemeka Anthony lyoke 3}

Peter Onubiwe $\mathrm{Nkwo}^{3}$

'Department of Obstetrics and Gynaecology, Federal Teaching Hospital Abakaliki, Abakaliki, ${ }^{2}$ Department of Obstetrics and Gynaecology, College of Health Sciences, Ebonyi State University, Abakaliki, ${ }^{3}$ Department of Obstetrics and Gynaecology, University of Nigeria Teaching Hospital, Enugu, Nigeria
Correspondence: Robinson Chukwudi Onoh

Department of Obstetrics and

Gynaecology, Federal Teaching Hospital PMB 102, Abakaliki, Ebonyi State, 4800I, Nigeria

Email onoh406@yahoo.com
Background: The global rise in cesarean delivery rate has been a major source of public health concern.

Aim: To appraise the cesarean deliveries and the associated fetal and maternal outcomes.

Materials and methods: The study was a case series with data collected retrospectively from the records of patients delivered by cesarean section at the Ebonyi State University Teaching Hospital, Abakaliki over a 10-year period, from January 2002 to December 2011. Ethical approval was obtained.

Results: Of 14,198 deliveries, 2,323/14,198 (16.4\%) were by cesarean deliveries. The overall increase of cesarean delivery was $11.1 / 10$ (1.1\%) per annum from 184/1,512 (12.2\%) in 2002 to $230 / 986(23.3 \%)$ in 2011. Of 2,097 case folders studied, 1,742/2,097 (83.1\%) were delivered at term, and in 1,576/2,097 (75.2\%), the cesarean deliveries were emergencies. The common indications for cesarean delivery were previous cesarean scars 417/2,097 (19.9\%) and obstructed labor 331/2,097 (15.8\%). There were 296 perinatal deaths, giving a perinatal mortality rate of $(296 / 2,197) 134.7 / 1,000$ births. Also, 129/2,097 (6.1\%) maternal case fatalities occurred, giving a maternal mortality rate of $908.6 / 100,000$ total births. Hemorrhage 57/129 (44.2\%) and sepsis $41 / 129(32.6 \%)$ were the major causes.

Conclusion: The study recorded a significant increase in cesarean delivery rate. Previous cesarean scars and obstructed labors were the main indications. Perinatal and maternal case fatalities were huge. Hence, there is need for continued community education for its reduction.

Keywords: cesarean delivery rate, unbooked, previous scar, case fatality, hemorrhage

\section{Introduction}

Cesarean delivery is a potentially lifesaving obstetric surgery when properly performed and following appropriate medical indications. ${ }^{1}$ The indications, however, vary widely, from country to country, although the heterogeneity in classifications does not allow for valid comparisons. ${ }^{2}$ These indications are often clinical factors such as maternal and obstetrical complications, previous cesarean delivery, dystocia, fetal distress, and abnormal presentations. ${ }^{3}$ Other contributors are temporal trends in maternal characteristics, such as increasing maternal age and higher rates of hypertension, diabetes, obesity, and multiple gestations. ${ }^{3}$ Still, factors such as improved surgical techniques, providers' and patients' perception of the safety of the procedure, patients' demands, physicians' practice patterns, and pressures on caregivers to practice defensive medicine have recently been implicated as indications. ${ }^{3}$ Some of these indications lead to the so-called unnecessary cesarean deliveries or cesarean deliveries purportedly done without there being clear medical indications. ${ }^{4}$ 
Compared to vaginal deliveries, cesarean deliveries are associated with huge challenges dependent on the setting. ${ }^{4,5}$ Cesarean delivery has been found to be associated with an intrinsic risk for severe short-term maternal outcomes, a risk that is higher in Africans. ${ }^{1}$ These are early complications and are prevalent in Africa due to poor health-seeking behavior, poverty, ignorance, and illiteracy. Cesarean delivery also increases the health risk for the babies, as well as the cost of health care. ${ }^{1,3}$ Furthermore, issues related to unnecessary cesarean deliveries have been topical in many countries because of their perceived contribution to the rise in cesarean delivery rates (CDRs). ${ }^{1}$

The World Health Organization (WHO) recommends that CDR should not exceed $15 \% .{ }^{6}$ Despite this, CDRs have been increasing worldwide over the past few decades with most countries and regions exceeding the WHO recommended rate of $15 \%$ of all deliveries. ${ }^{3,7}$ Reports from Nigeria show increases in CDRs, with rates in excess of the $15 \%$ recommendation by WHO, although some centers document rates less than $15 \%$, thus suggesting that the rising CDR may not truly be universal. ${ }^{7-12}$ A 3-year study from this center published about half a decade ago found the CDR to be in excess of $15 \%$ and showed a rising trend, with previous cesarean section accounting for more than $19 \%$ of the indications. ${ }^{13}$

This study aims to determine the 10-year, 5-year, and annual CDRs in a university teaching hospital in southeast Nigeria, with a view to confirm above findings, to compare these findings with reports from elsewhere in Nigeria and beyond, and to assess the indications for the maternal and fetal outcomes associated with cesarean deliveries over the 10 -year period. Conclusions will be drawn and recommendations made based on findings.

\section{Materials and methods}

There were two tertiary hospitals in Abakaliki, southeast Nigeria; the Ebonyi State University Teaching Hospital (EBSUTH) and the Federal Medical Centre. Both hospitals merged in 2012 to form the Federal Teaching Hospital, Abakaliki. This study was conducted at EBSUTH.

Abakaliki is the capital of Ebonyi state. The main occupations of the people of Ebonyi state are farming, fishing, and petty trading. The majority live in rural communities, and poverty is rife. Ebonyi state is one of the five states in southeast Nigeria.

EBSUTH offered tertiary health care services to Ebonyi state and other neighboring states of Abia, Akwa Ibom, Cross River, and Enugu. It had a high obstetric patient load mainly due to the state government's free maternal health care scheme.
The obstetrics unit was well funded and had five teams with three attending consultants (specialists) in each team.

This was a case series with data collected retrospectively from all the cesarean deliveries done over a 10-year period from January 2002 to December 2011. The author trained five research assistants who are resident doctors in obstetrics and gynecology on data collection and recording. The delivery register was used to select all women who had cesarean delivery, and their folders were retrieved from the record department. The delivery register contained all information on sociodemographic variables. In the event of missing information from the folder or missing of a sheet of the folder, such information was sourced from the nurses' hand over notes from different sections of the obstetrics unit with reference to the delivery register. The record unit of the hospital was well organized, and patient's folders were stacked using serial numbering. These folders were highly confidential. The research assistants in collaboration with the authors recorded the information about the patient in a moderately sized register (notebook) with subheadings of all the information needed. Each research assistant collected information over a 2-year period under guidance by a particular author while the first author supervised the data collection. Data collected were submitted to the hospital research unit for statistical recording and analysis. Data collection sheet was used to capture the sociodemographic variables as well as the characteristics and outcomes of the cesarean deliveries. The patients' folders, antenatal ward, labor ward, theater, postnatal ward, and newborn special intensive care unit registers were utilized for the data collection. The indications for cesarean delivery were recorded in the delivery register, operating notes, and ward register. The indications could be one or multiple depending on the findings at the point of decision for delivery and were recorded as such. All the cases were individualized and were treated based on findings. The diagnosis for cesarean delivery was made by the attending consultant obstetrician or senior registrar but the decision for cesarean delivery was made by the consultant. Patients who accessed antenatal care at the hospital (EBSUTH) were classified as booked while those who had not accessed antenatal care services at the hospital were regarded as unbooked. Two or more previous cesarean sections were considered as absolute indications for a repeat elective cesarean section while one previous cesarean section due to a nonrecurrent factor was selected for trial of vaginal birth after a previous cesarean delivery. Elective cesarean deliveries were regarded as cesarean deliveries scheduled from the antenatal clinic and fixed at 
a convenient date for the pregnant mother and the fetus as well as the surgeon, while emergency cesarean deliveries were those scheduled because there was a threat to life for the mother and/or fetus. The surgeries were done by the consultant obstetrician or the senior registrar under supervision of the consultant. Spinal or general anesthesia was used for the surgeries with a preference for spinal except when there was a contraindication to spinal or in cases of failed spinal anesthesia. The consultant anesthesiologist or residents and nurse anesthetics under supervision by the consultant administered the anesthesia. Fetal distress was diagnosed by intermittent fetal heart auscultation with Pinard stethoscope when the reading was persistently greater than 160 beats/min or less than 100 beats/min. Fetal heart auscultation was monitored every 5 minutes in fetal distress with active resuscitation and management. This would be reviewed after 30 minutes for continuation of labor or for delivery by emergency cesarean delivery. For high-risk pregnant women in labor fetal heart rate (FHR) were monitored every 15 minutes while those with no risk were auscultated every 30 minutes. Prolonged labor was diagnosed using the WHO partograph, while obstructed labor was diagnosed based on clinical findings like significant molding and caput with or without edematous vulva. Precious pregnancies were regarded as pregnancies conceived after prolonged infertility, conception by assisted reproductive technique, and pregnancies in elderly primigravida. All delivered infants were handed over to the attending neonatologist who records the Apgar score and resuscitated the infant when necessary.
The blood loss after cesarean delivery session was estimated based on the number and extent of sterile abdominal mop and gauze soaked after the operation. A well-soaked sterile abdominal mop and gauze was estimated as $100 \mathrm{~mL}$ and $10 \mathrm{~mL}$, respectively. Gauze was used before reaching the peritoneal cavity while sterile abdominal mop was used within the peritoneal cavity. Intraoperative blood loss of $1,000 \mathrm{~mL}$ was considered an indication for blood transfusion. Hemodynamic instability, postpartum hemorrhage, and postoperative hemoglobin indicating severe or moderate anemia were also considered as indications for blood transfusion. Maternal deaths recorded in the hospital from delivery to 6 weeks after delivery were used to calculate the maternal mortality rate. Autopsies were not done for the maternal death because of cultural belief, poverty, and illiteracy in our setting. Statistical analysis was done with SPSS version 15 . Chi-square test was used to determine the level of significance. Level of significance was set at $P$-value $<0.05$. Univalent and multivariate analysis was done to obtain simple percentages and inferential statistics.

The study was approved by the hospital's research and ethics committee.

\section{Results}

Of 14,198 deliveries during the 10-year study period, 2,323 were cesarean deliveries, giving a CDR of 2,323/14,198 $(16.4 \%)$.

Table 1 shows the trend in CDR. From a low value of $184 / 1,512(12.2 \%)$ in 2002 , the annual CSR increased to

Table I Trend of cesarean delivery over a I0-year period 2002-20II at EBSUTH

\begin{tabular}{|c|c|c|c|}
\hline Years & Total deliveries & Number of cesarean deliveries, $\mathbf{N}$ (\%) & Perinatal mortality rate, ${ }^{a} \mathrm{~N}(\times 1,000$ births $)$ \\
\hline 2002 & 1,512 & $184(12.2)$ & $56(37.0)$ \\
\hline 2003 & $\mathrm{I}, 722$ & $243(14.1)$ & $68(39.5)$ \\
\hline 2004 & 2,325 & $363(15.6)$ & $54(27.5)$ \\
\hline 2005 & $\mathrm{I}, 728$ & $305(17.7)$ & $138(79.9)$ \\
\hline 2006 & 1,550 & $242(15.6)$ & $90(58.1)$ \\
\hline 2007 & 1,228 & $231(18.8)$ & $119(96.9)$ \\
\hline 2008 & 1,189 & $245(20.6)$ & $78(65.6)$ \\
\hline 2009 & 1,196 & 154 (I2.9) & $70(88.5)$ \\
\hline 2010 & 762 & $126(16.5)$ & $61(80.0)$ \\
\hline 2011 & 986 & $230(23.3)$ & $88(89.2)$ \\
\hline $2002-2011$ & 14,198 & $2,323(16.4)$ & $822(57.9)$ \\
\hline \multicolumn{4}{|c|}{ Chi-square test for the comparisons } \\
\hline \multicolumn{4}{|c|}{ Comparison of 2002 and 2011} \\
\hline 2002 & $1,5 \mid 2$ & $184(12.2)$ & $<0.001$ \\
\hline 2011 & 986 & $230(23.3)$ & \\
\hline \multicolumn{4}{|c|}{ Comparison of 5-year interval } \\
\hline $2002-2006$ & 8,837 & I,337 (I5.I) & $<0.001$ \\
\hline $2007-2011$ & 5,361 & $986(18.4)$ & \\
\hline
\end{tabular}

Note: aPerinatal mortality rate means fetal death from age of viability to I week postdelivery per I,000 births. Abbreviation: EBSUTH, Ebonyi State University Teaching Hospital. 


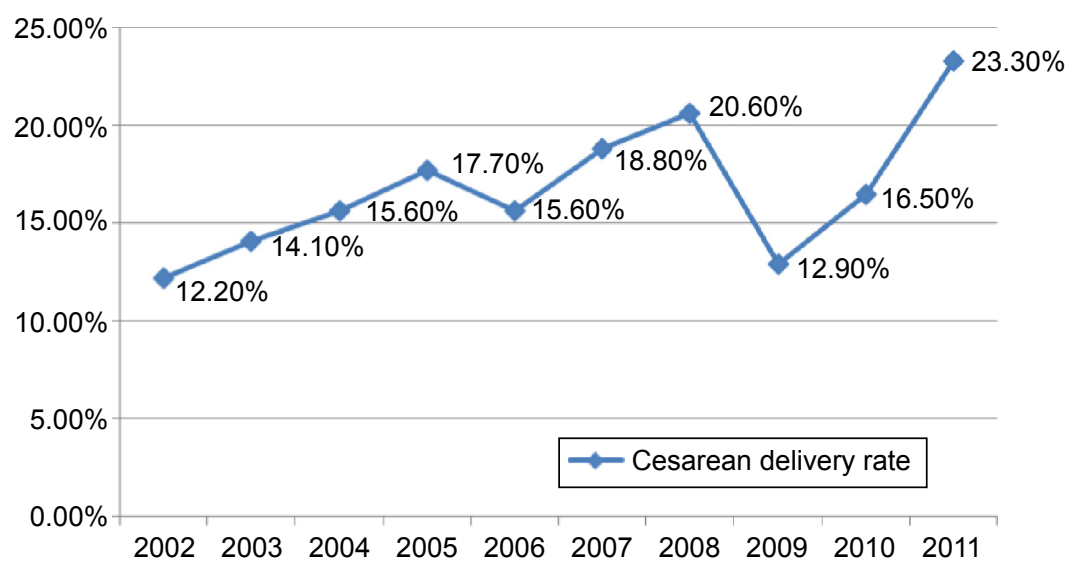

Figure I Annual cesarean delivery rate over a 10-year period 2002-20 I I at EBSUTH.

Abbreviation: EBSUTH, Ebonyi State University Teaching Hospital.

$305 / 1,728(17.7 \%)$ in 2005 , dropped to $242 / 1,550(15.6 \%)$ in 2006 , increased again to $245 / 1,189(20.6 \%)$ in 2008 , dropped sharply to $154 / 1,196(12.9 \%)$ in 2009 , and then increased steeply to 230/986 (23.3\%) in 2011 (Figure 1). The $11.1 \%$ increase in CDR from $12.2 \%$ in 2002 to $23.3 \%$ in 2011 was statistically significant, with $P<0.001$. It translated to a $11.1 / 10(1.1 \%)$ annual increase in CDR. The 5-year CDR showed a $3.3 \%$ increase from $1,337 / 8,837(15.1 \%)$ in 2002-2006 to 986/5,361 (18.4\%) in 2007-2011, which was statistically significant, with $P<0.001$.

Just 2,097 (90.3\%) case folders out of the 2,323 that had cesarean sections could be retrieved and were analyzed. Table 2 shows the patients' ages, parity, booking status, gestational ages at delivery, and the nature of cesarean sections performed on them. The patients' ages ranged from 16 to 43 years, with a mean age of $27.4(4.9)$ years. The modal age group was 25-29 years in 872/2,097 (41.6\%) patients. The parity ranged from 0 to 11 , with a mean of 2.2 (standard deviation 2.1). Majority, 1,122/2,097 (53.5\%), were multipara (para 1-4). A total of 1,249/2,097 (59.7\%) booked for antenatal care, 1,742/2,097 (83.1\%) of the deliveries were at term (37-41 weeks plus 6 days), and 1,576/2,097 (75.2\%) of the surgeries were emergency deliveries.

Table 3 shows the indications for cesarean delivery. Some patients had multiple indications. Previous cesarean scar, the most common indication, was documented in $417 / 2,097$ (19.9\%) of the cases. Other major indications were obstructed labor, poor progress in labor, fetal distress, prolonged labor, cephalopelvic disproportion, hypertensive diseases in pregnancy, breech presentation, placenta previa, and transverse lie (Table 3 ).

A total of 2,197 babies were delivered through cesarean section, consisting of 1,998 singletons, 98 sets of twins, and one set of triplets; 1,272/2,197 (57.9\%) of the babies were males. The majority of the babies, 1,667/2,197 (75.9\%), weighed between 2,500 $\mathrm{g}$ and 3,999 $\mathrm{g}$. A total of 1,253/2,197 (57.0\%) and 281/2,197 (12.8\%) had 1st-minute Apgar scores of 7-10 and 0 , respectively. At 5th minute, 1,667/2,197 (75.9\%) and 296/2,197 (13.5\%) had Apgar scores of 7-10 and 0 , respectively. Thus, the stillbirth rate was $296 / 2,197$ (13.5\%), translating to a perinatal mortality rate of 296/2,197 (134.7/1,000) deliveries, live and stillbirths. The total live births following cesarean deliveries were 1,901/2,197 $(86.5 \%)$ (Table 4).

Table 2 Main characteristics of 2,097 cases of cesarean delivery performed at EBSUTH over a 10-year period (2002-20I I)

\begin{tabular}{|c|c|c|c|}
\hline Item & $N(\%)(N=2,097)$ & Range & Mean $( \pm S D)$ \\
\hline \multicolumn{4}{|l|}{ Age (years) } \\
\hline$\leq 19$ & $107(5.1)$ & & \\
\hline $20-24$ & $444(2 \mid .2)$ & $16-43$ & $27.4( \pm 4.9)$ \\
\hline $25-29$ & $872(4 I .6)$ & & \\
\hline $30-34$ & $600(28.6)$ & & \\
\hline$\geq 35$ & $74(3.5)$ & & \\
\hline \multicolumn{4}{|l|}{ Parity } \\
\hline 0 & $608(29.0)$ & & \\
\hline $\mathrm{I}-4$ & $\mathrm{I}, 122(53.5)$ & $0-11$ & $2.2( \pm 2.1)$ \\
\hline$\geq 5$ & $367(17.5)$ & & \\
\hline \multicolumn{4}{|l|}{ Booking status } \\
\hline Booked & $1,249(59.7)$ & & \\
\hline Unbooked & $848(40.3)$ & & \\
\hline \multicolumn{4}{|c|}{ Gestational age at delivery (weeks) } \\
\hline$<37$ (preterm) & $165(7.9)$ & & \\
\hline 37 to $<42$ (term) & $1,742(83.1)$ & & \\
\hline$\geq 42$ (postterm) & $190(9.0)$ & & \\
\hline \multicolumn{4}{|l|}{ Nature of CS } \\
\hline Emergency & $\mathrm{I}, 576(75.2)$ & & \\
\hline Elective (all booked) & $521(24.8)$ & & \\
\hline
\end{tabular}

Abbreviation: EBSUTH, Ebonyi State University Teaching Hospital; CS, Cesarean section; SD, standard deviation. 
Table 3 The indications for the cesarean deliveries in 2,097 cases delivered at EBSUTH over a 10-year period (2002-201 I)

\begin{tabular}{|c|c|}
\hline Indications & $\mathbf{N}(\%)$ \\
\hline Previous cesarean scar & $417(19.9)$ \\
\hline Obstructed labor & $331(15.8)$ \\
\hline Poor progress/prolonged in labor & $236(11.3)$ \\
\hline Fetal distress & $219(10.4)$ \\
\hline Cephalopelvic disproportion & $173(8.2)$ \\
\hline Hypertensive diseases in pregnancy & $162(7.7)$ \\
\hline Breech presentation & $150(7.2)$ \\
\hline Placenta previa & $137(6.5)$ \\
\hline Transverse lie $e^{b}$ & $122(5.8)$ \\
\hline Multiple pregnancy & $99(4.7)$ \\
\hline Cord prolapse & $55(2.6)$ \\
\hline Precious pregnancy & $52(2.5)$ \\
\hline Fetal macrosomiac & $25(1.2)$ \\
\hline Postterm pregnancy & $20(1.0)$ \\
\hline Previous VVF repair & $8(0.4)$ \\
\hline Uterine fibroids & $4(0.2)$ \\
\hline Intrauterine growth restriction & $4(0.2)$ \\
\hline Premature rupture of membranes & $4(0.2)$ \\
\hline Retained second twin & $4(0.2)$ \\
\hline Fetal anomaly & $4(0.2)$ \\
\hline Placental abruption & $3(0.14)$ \\
\hline Preterm pregnancies & $3(0.14)$ \\
\hline Cervical cancer & $\mathrm{I}(0.05)$ \\
\hline Vulval warts & $\mathrm{I}(0.05)$ \\
\hline
\end{tabular}

Table 5 shows the intraoperative blood loss, frequency of blood transfusion, maternal case fatality, and causes of maternal death among 2,097 mothers delivered by cesarean section. A total of 975/2,097 (46.5\%) had estimated blood loss of $500-1,000 \mathrm{~mL}$ and $80 / 2,097(3.8 \%)$ in excess of $1,000 \mathrm{~mL}$, and 982/2,097 (46.8\%) received various units of blood transfusion. One hundred and twenty-nine (6.1\%) maternal case fatalities occurred. Some of the fatalities had multiple causes. The main causes of maternal deaths were hemorrhage and severe anemia $(57 / 129,44.2 \%)$, overwhelming infection (41/129, 36.2\%), and hypertensive diseases. In $14 / 129$ (10.9\%) patients, the cause of death was uncertain. A total of 129/2,097 (6.1\%) maternal case fatalities occurred, giving a maternal mortality rate of 908.6/100,000 births.

\section{Discussion}

CDR depends on the inherent characteristics of the obstetrics population, sociodemographic pattern, departmental policies on dystocia, breech, fetal distress and previous cesarean scars, and consideration of maternal choice and wishes, among others. ${ }^{10}$ This study showed that the 10 -year CDR,
Table 4 Outcome of 2,097 cesarean deliveries performed over a I0-year period (2002-20I I) at EBSUTH

\begin{tabular}{ll}
\hline Characteristics & $\mathbf{N}(\%)$ \\
\hline Sex & \\
Male & $\mathrm{I}, 272(57.9)$ \\
Female & $925(42.1)$ \\
Weight $(\mathrm{g})$ & \\
$\leq 2,499$ & $408(\mathrm{I} 8.6)$ \\
$2,500-3,999$ & $\mathrm{I}, 667(75.9)$ \\
$4,000-4,499$ & $97(4.4)$ \\
$\geq 4,500$ & $25(1.1)$ \\
Apgar scores & Ist minute \\
$7-10$ & $\mathrm{I}, 253(57.0)$ \\
$\mathrm{I}-6$ & $663(30.2)$ \\
0 & $28 \mathrm{I}(\mathrm{I} 2.8)$ \\
Apgar scores & 5 th and I0th minutes \\
$7-10$ & $\mathrm{I}, 668(75.9)$ \\
$\mathrm{I}-6$ & $233(10.6)$ \\
0 & $296(\mathrm{I} 3.5)$ \\
\hline
\end{tabular}

Abbreviation: EBSUTH, Ebonyi State University Teaching Hospital.

5-year CDRs, and the annual CDRs for 7 out of the 10 years were higher than the $15 \%$ recommendation by WHO. ${ }^{6}$ Also, the 5-year and annual CDRs showed rising trends of 3.3\% and $1.1 \%$, respectively. The CDR in the first 5 -year period was lower than the $18.4 \%$ 3-year CDR previously reported from the center, but that for the second 5-year period tallied with it. ${ }^{13}$ The 10 -year CDR for this study was lower than 18.5\% 10-year CDR from Nnewi in southeast Nigeria, but much higher than the $9.1 \% 10$-year rate from Ilorin in north-central Nigeria about a decade earlier..$^{14,15}$ The 10-year, 5-year, and annual CDRs in this study were all higher than

Table 5 Intraoperative blood loss, frequency of blood transfusion, maternal case fatality, and causes of maternal death among mothers delivered by cesarean delivery over a 10-year period 2002-20I I at EBSUTH

\begin{tabular}{ll}
\hline Outcome & $\mathbf{N}(\%) \mathbf{( N = 2 , 0 9 7 )}$ \\
\hline $\begin{array}{ll}\text { Intraoperative blood loss }(\mathrm{mL}) \\
\quad<500\end{array}$ & $\mathrm{I}, 042(49.7)$ \\
$500-1,000$ & $975(46.5)$ \\
$>1,000$ & $80(3.8)$ \\
Frequency of blood transfusion (units of blood) & \\
$\quad \leq 2$ & $847(40.4)$ \\
$\geq 3$ & $135(6.4)$ \\
Total & $982(46.8)$ \\
Maternal case fatality associated with & $129(6.1 \%)$ \\
cesarean section & \\
Causes of maternal death (some had multiple causes) \\
$\quad$ Hemorrhage and severe anemia \\
$\quad$ Overwhelming infection & $57(44.2)$ \\
Hypertensive diseases & $41(32.6)$ \\
Cause of death uncertain & $39(30.2)$ \\
\hline
\end{tabular}

Abbreviation: EBSUTH, Ebonyi State University Teaching Hospital. 
the $9.9 \%$ 5-year and $11.8 \%$ 9-year CDRs from Maiduguri ${ }^{11}$ and Sokoto ${ }^{12}$ in northern Nigeria, but lower than the $25 \%$ 3 -year rate reported from Enugu ${ }^{8,16}$ in southeast, and 35.9\% 6 -year rate from Osogbo ${ }^{17}$ in southwest Nigeria. All the CDRs from this study were lower than rates from Tanzania ${ }^{5,18}$ in East Africa, Sri Lanka ${ }^{19}$ and People's Republic of China ${ }^{20}$ in Asia, and Latin America, ${ }^{21}$ but demonstrate rising trends that could escalate if not checked. The sharp drop in CDR in 2006 could have been due to the removal of free maternal health care services by the state government, which made most complicated labor cases from the rural setting to resort to other peripheral (mainly mission) hospitals. This buttresses the fact that most of the cesarean delivery and poor feto-maternal outcome that occurred in this study were following mismanaged or poorly managed pregnancy and labor processes. Also in 2009, the hospital had an upward review of the hospital bills as well as the policy for blood banking system (husband to provide a unit of blood for her pregnant wife or its financial equivalent) and these made most pregnant women resort to peripheral hospital for delivery, especially those who were unbooked and had complication necessitating comprehensive obstetric care. This resulted in reduction in the CDR still supporting the fact that most cesarean deliveries are for poorly managed labor. Most of these poorly managed labor processes occur due to poor health-seeking behavior, ignorance, poverty, and illiteracy.

More than $75 \%$ of the cesarean deliveries in this study were for emergency indications, despite the fact that more than $70 \%$ of the patients were booked. This finding was similar to reports from elsewhere in Nigeria. ${ }^{22}$ In fact, this and several studies from within and outside Nigeria showed that emergency cesarean delivery contributed hugely to the rising trend in CDR. ${ }^{10,12-14}$ Majority of the emergency cesarean deliveries in this study were either in unbooked parturient women whose labor were poorly managed elsewhere by unskilled birth attendants or in booked parturient mothers who decided to deliver in peripheral settings not minding the birth plan but returned after complications developed.

Previous cesarean scar was the commonest indication for cesarean deliveries in this study as in other studies. ${ }^{9,10}$ Thus, previous cesarean scars are currently assuming an increasing role as indications of cesarian sections. This may be because two or more previous cesarean sections were regarded as absolute indications for a repeat cesarean section in our setting. Other common indications documented were obstructed labor, poor progress or prolonged labor, fetal distress, cephalopelvic disproportion, breech presentation, abruption placenta, transverse/oblique lie, twin gestation, eclampsia, and pregnancy-induced hypertension. Fetal distress, the commonest fetal indication for cesarean sections in this study, has also been reported as the commonest fetal indicator for emergency cesarean delivery in Nigeria. ${ }^{11-17}$ Fetal distress and obstructed labor may have contributed greatly to the high perinatal mortality rate seen in this study. Hence, improved supervision in labor with modern equipment and improved health-seeking behavior may result in reduction of perinatal mortality rate.

The perinatal mortality rate in this study was high with a range of 27.5-96.9/1,000 deliveries. The rising trend of cesarean delivery did not result in a downward trend of perinatal mortality rate. This still buttresses the fact that most cesarean deliveries in this study were done when there were already existed fetal compromise either in booked or unbooked cases with resultant poor fetal outcome. The reason could be because of poor fetal monitoring, injudicious use of oxytocics, unavailability of equipment for early diagnosis of fetal compromise, poor referral network, especially from the rural to tertiary institutions in the urban area, and serious difficulties with transportation from the hinterlands. High-risk pregnancies (primigravida, grand multipara, teenage pregnancy, and preeclampsia) were also common in this study and might have contributed to the increase in cesarean section rate as well as perinatal mortality rate, especially when such pregnancies were not recognized as potential contributors to poor feto-maternal outcome. The overall maternal mortality in this study was high even though there has been a downward trend over the last 5 years. It is pertinent to note that the initial objective of this study was to access the cesarean section rate, its indications, and trend over the study period, but the findings of high maternal and perinatal mortality rate surpassed the importance of this initial theme.

Birth asphyxia was a common finding at the 1st minute of delivery in this study with marked reduction at 5 th minute after resuscitation. The 1st-minute score determined how well the baby tolerated the birthing process while 5th-minute score showed how well the baby tolerated extra uterine life. A low score on the 1st-minute Apgar may show that the neonate requires medical attention but does not necessarily indicate a long-term problem, particularly if the score improves at the 5 th minute. This was the scenario in this study. It buttressed the fact that the processes of labor and delivery in our setting need improvement. Good referral system, active management of labor, and essential obstetrics care will be of immense help in improving the processes of labor and delivery with a resultant reduction in birth asphyxia. 
However, an Apgar score that remains below 3 at 10 minutes, 15 minutes, or 30 minutes might indicate longer-term neurological damage, including a small but significant increase in the risk of cerebral palsy. Generally, the Apgar score determines quickly whether a newborn needed immediate medical care. It is not designed to predict long-term health issues.

Also, low-birth-weight babies were common findings in this study and instituting adequate and specialized antenatal care to selected cases as well as in the high-risk pregnancies may help in reducing such deliveries. This will also help in reducing the rising CDR as well as the high perinatal mortality rate. In India, an upward trend of perinatal mortality rate was noted with a higher perinatal mortality rate in cesarean birth since the early 1990 s due to privatization of care, liberal cesarean section policy for very low-birth-weight babies, and in women with compromised fetus. ${ }^{14}$

Maternal complication like postpartum hemorrhage was a significant finding following cesarean section in most developing countries. ${ }^{18-20}$ This is similar to our findings in this study as postpartum hemorrhage accounted for $3.8 \%$ of postoperative blood loss. Also, hemorrhage and severe anemia were the commonest causes of maternal mortality in this study. Patient's selection, good referral system, and good health-seeking behavior will help in reducing emergency cesarean section with its attendant complications.

The CDR in this study was high with a steady rising trend, and this did not result in reduction of perinatal mortality rate. This implies that there is urgent need to reduce the number of unbooked cases and emergency cesarean section as this contributes greatly to poor fetal-maternal outcome. However, there is limitation to the conclusion derived from this study as the study was a case series.

We, therefore, recommend that health education, women empowerment, adequate counseling, better patient selection, specialized antenatal care for high-risk pregnancies, and proper supervision of patients in labor will help in reducing the high cesarean section rate seen in this study. ${ }^{9}$ This will also help to improve the feto-maternal outcome.

\section{Acknowledgments}

We wish to acknowledge the management of Federal Teaching Hospital Abakaliki, Ebonyi State Nigeria, for providing the enabling environment for this study and our gratitude goes to the departmental consultants and resident doctors who supported us in the course of this research.

\section{Disclosure}

The authors report no conflicts of interest in this work.

\section{References}

1. Souza JP, Gülmezoglu A, Lumbiganon P, et al; WHO Global Survey on Maternal and Perinatal Health Research Group. Cesarean section without medical indications is associated with an increased risk of adverse short-term maternal outcomes: the 2004-2008 WHO Global Survey on Maternal and Perinatal Health. BMC Med. 2010;8(1):71.

2. Farine D, Shepherd D. Classification of cesarean sections in Canada: the modified Robson criteria, SOGC Committee Opinion. J Obstet Gynecol Can. 2012;34(10):976-979.

3. Kelly S, Sprague A, Fell DB, et al. Examining cesarean section rates in Canada using the Robson Classification System. J Obstet Gynecol Can. 2013;35(3):206-214.

4. Richard F, De Brouwere V. Non-Clinical Interventions for Reducing Unnecessary Cesarean Section: RHL Commentary. Geneva: World Health Organization, The WHO Reproductive Health Library; 2012.

5. Litorp H, Kidanto HL, Nystrom L, Darj E, Essén B. Increasing cesarean section rates among low-risk groups: a panel study classifying deliveries according to Robson at a university hospital in Tanzania. $B M C$ Pregnancy Childbirth. 2013;13:107.

6. Chalmers B. WHO appropriate technology for birth revisited. $\mathrm{Br}$ J Obstet Gynaecol. 1992;99:709-710.

7. Betrán AP, Gulmezoglu AM, Robson M, et al. WHO Global Survey on maternal and perinatal health in Latin America: classifying cesarean sections. Reprod Health. 2009;6:18.

8. Nkwo PO, Onah HE. Feasibility of reducing the cesarean section rate at the University of Nigeria Teaching Hospital, Enugu, Nigeria. Trop J Obstet Gynecol. 2002;19:86-89.

9. Ibekwe PC. Rising trends in cesarean section rates: an issue of major concern in Nigeria. Niger J Med. 2004;13(2):180-181.

10. Oladapo OT, Sotunsa JO, Sule-Odu AO. The rise in cesarean birth rate in Sagamu, Nigeria: reflection of changes in obstetric practice. J Obstet Gynecol. 2004;24(4):377-381.

11. Geidam AD, Audu BM, Kawuwa BM, Obed JY. Rising trend and indications of cesarean section at the University of Maiduguri Teaching Hospital, Nigeria. Ann Afr Med. 2009;8:127-132.

12. Nwobodo EI, Isah AY, Panti A. Elective cesarean section in a tertiary hospital in Sokoto, north western Nigeria. Niger Med J. 2011;52(4): 263-265.

13. Agwu UM, Umeora OUJ, Umahi G. A reappraisal of the indications for abdominal delivery at a referral health institution in southeast Nigeria. Trop J Obstet Gynecol. 2009;26(1):68-74.

14. Eleje GU, Udigwe GO, Akabuike JC, Eke AC, Eke NO, Umeobika JC. The rate of cesarean section in Nnewi, Nigeria: a 10-year review. Afrimed Journal. 2010;1(1):11-14.

15. Ijaiya MA, Aboyeji PA. Cesarean delivery: the trend over a 10-year period at Ilorin, Nigeria. Niger J Surg Res. 2001;3(1):11-18.

16. Okezie AO, Oyefara B, Chigbu CO. A 4-year analysis of cesarean delivery in a Nigeria Teaching Hospital. One quarter of babies born surgically. J Obstet Gynecol. 2007;27(5):470-474.

17. Adekunle A, Adeyemi AS, Fasanu AO. Cesarean section at a tertiary institution in southwest Nigeria. Open J Obstet Gynecol. 2013;3: $357-361$.

18. Worjoloh A, Manongi R, Oneko O, Hoyo C, Daltveit AK, Westreich D. Trends in cesarean section rates at a large East African referral hospital from 2005-2010. Open J Obstet Gynecol. 2012;2:255-261.

19. Goonewardene M, Kumara DMA, Arachchi DRJ, Vithanage R, Wijeweera R. The rising trend in cesarean section rates: should we and can we reduce it? Sri Lanka J Obstet Gynecol. 2012;34:11-18.

20. Gao Y, Xue Q, Chen G, Stone P, Zhao M, Chen Q. An analysis of the indications for cesarean section in a teaching hospital in China. Eur J Obstet Gynecol Reprod Biol. 2013;170(2):414-418.

21. World Health Organization. Rising Cesarean Deliveries in Latin America: How Best to Monitor Rates and Risks. Geneva: WHO; 2009.

22. Okafor CI, Onwosulu DN. Rising cesarean section rate: any hope for decline? NAUTH Nnewi experience. NMJ. 2006;47:38-40. 
International Journal of Women's Health

Dovepress

\section{Publish your work in this journal}

The International Journal of Women's Health is an international, peerreviewed open-access journal publishing original research, reports, editorials, reviews and commentaries on all aspects of women's healthcare including gynecology, obstetrics, and breast cancer. The manuscript management system is completely online and includes

a very quick and fair peer-review system, which is all easy to use Visit http://www.dovepress.com/testimonials.php to read real quotes from published authors.

Submit your manuscript here: http://www.dovepress.com/international-journal-of-womens-health-journal 